Research article

Open Access

\title{
Antisense oligonucleotides targeting the progesterone receptor inhibit hormone-independent breast cancer growth in mice
}

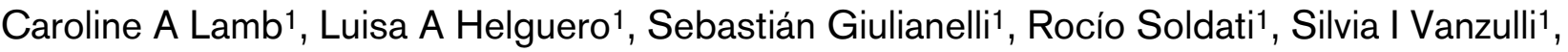 \\ Alfredo Molinolo ${ }^{1,2}$ and Claudia Lanari ${ }^{1}$
}

\begin{abstract}
${ }^{1}$ Instituto de Biología y Medicina Experimental (Consejo Nacional de Investigaciones Científicas y Técnicas (CONICET)), Buenos Aires, Argentina 2Oral and Pharyngeal Cancer Branch, National Institute of Dental and Craniofacial Research, National Institutes of Health, Bethesda, Maryland, USA

Corresponding author: Claudia Lanari, clanari@dna.uba.ar

Received: 17 May 2005 Revisions requested: 22 Jul 2005 Revisions received: 9 Sep 2005 Accepted: 6 Oct 2005 Published: 9 Nov 2005

Breast Cancer Research 2005, 7:R1111-R1121 (DOI 10.1186/bcr1345)

This article is online at: http://breast-cancer-research.com/content/7/6/R1111

(c) 2005 Lamb et al.; licensee BioMed Central Ltd.

This is an open access article distributed under the terms of the Creative Commons Attribution License (http://creativecommons.org/licenses/by/2.0), which permits unrestricted use, distribution, and reproduction in any medium, provided the original work is properly cited.
\end{abstract}

\begin{abstract}
Introduction Previous data from our laboratory suggested that progesterone receptors (PRs) are involved in progestinindependent growth of mammary carcinomas. To investigate this possibility further, we studied the effects of PR antisense oligodeoxynucleotides (asPR) on in vivo tumor growth.

Method BALB/c mice with subcutaneous $25 \mathrm{~mm}^{2}$ mammary carcinomas expressing estrogen receptor- $\alpha$ and $\mathrm{PR}$ were either injected intraperitoneally with $1 \mathrm{mg}$ asPR every 24 or 12 hours for 5-10 days, or subcutaneously with RU 486 (6.5 mg/kg body weight) every 24 hours. Control mice received vehicle or scPR.

Results Significant inhibition of tumor growth as well as a significant decrease in bromodeoxyuridine uptake was observed in asPR-treated mice, which correlated with histological signs of

regression and increased apoptosis. Mice treated with RU 486 experienced almost complete tumor regression. No differences were detected between vehicle-treated and scPR-treated mice. Anti-progestin-treated and asPR-treated mice were in a continuous estrous/meta-estrous state. Decreased phosphorylated extracellular signal-regulated kinase (ERK) 1 and ERK2 levels and estrogen receptor- $\alpha$ expression were observed as late events in RU 486-treated and asPR-treated mice with regressing tumors.

Conclusion We demonstrate, for the first time, inhibition of tumor growth in vivo using asPR. Our results provide further evidence for a critical and hierarchical role of the PR pathway in mammary carcinomas.
\end{abstract}

\section{Introduction}

The predominant role assigned to the estrogen receptor (ER)$\alpha$ pathway as the key player in the origin and maintenance of the neoplastic phenotype in mammary cancer has been challenged by recent clinical [1-4] and experimental [5] findings, which suggest that progesterone receptors (PRs) play a similarly significant role. We and others have demonstrated in female mice that progesterone, as well as the synthetic progestin medroxyprogesterone acetate (MPA), can directly induce mammary carcinomas or act as a co-carcinogen [610]. We found clear differences in target cells or in the type of tumors induced by progesterone or MPA in mouse mammary gland [6], even though both agents are similarly able to promote hormone-dependent growth [11]. MPA induces mam- mary tumors that are quite similar to human breast cancers, specifically metastatic carcinomas of ductal histology, preceded by ductal pre-neoplastic lesions, which maintain high levels of ER- $\alpha$ and PRs and may progress through different stages of hormone responsiveness [12-14]. Progesterone, on the other hand, induces lobular mammary carcinomas, which lose hormone receptor expression after serial transplantations [6].

In previous reports we suggested that PRs are essential in the maintenance of the neoplastic phenotype of MPA-induced mammary carcinomas $[14,15]$, even in tumors that have progressed to a hormone-independent phenotype [16]. Moreover, we also demonstrated that the PR pathway is also used by

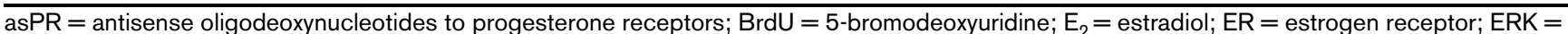
extracellular signal-regulated kinase; MAPK = mitogen-activated protein kinase; MPA = medroxyprogesterone acetate; PBS = phosphate-buffered saline; PR = progesterone receptor; scPR = scrambled oligodeoxynucleotides to progesterone receptors. 
basic fibroblast growth factor to exert growth stimulatory effects [17]. Antisense oligodeoxynucleotides designed to block both PR isoforms (asPR) confirmed that PRs are involved in the basic fibroblast growth factor proliferative pathway in these cells [17]. This interaction between growth factors and PRs was recently confirmed by Labriola and coworkers [18], who demonstrated activation of PRs by mitogen-activated protein kinase (MAPK) using both our murine cells and T47D human cells; and by Qiu and coworkers [19], who demonstrated that activation of MAPK in human cells induced Ser294 phosphorylation and rapid nuclear translocation.

To further define the role played by the stimulatory effects of PRs in hormone-independent tumors within an experimental therapeutic scenario, we expanded our in vitro studies by blocking PRs with phosphorothiolated oligodeoxynucleotides to PR (i.e. asPR). Furthermore, we extended these findings to three different progestin-independent tumor lines in order to elucidate the involvement of PRs in the growth of such tumors. The goal of the present study was to investigate the in vivo effect of asPR on tumor growth.

\section{Materials and methods Animals}

Two-month-old virgin female BALB/c mice (Instituto de Biología y Medicina Experimental Animal Facility, Buenos Aires, Argentina) were used. The animals were housed in groups of four per cage in an air-conditioned room at $20 \pm 2^{\circ} \mathrm{C}$ under a 12-hour light/dark cycle, and had free access to food and tap water. Animal care and manipulation were in accordance with institutional guidelines and with the Guide for the Care and Use of Laboratory Animals [20].

\section{Tumors}

Four different MPA-induced mammary ductal carcinomas were used, namely 59-2-HI, 32-2-HI, C7-2-HI and CC4-HI $[13,21]$, which were maintained by serial subcutaneous implantation into BALB/c virgin female mice. These tumors belong to the group of responsive progestin-independent tumors; they do not need administration of exogenous hormones to grow but they regress when they are treated with estradiol $\left(E_{2}\right)$, RU 38486 (RU 486), or ZK 98299 (ZK 299) [22].

\section{Reagents}

The reagents used in Western blots were purchased from Gibco BRL (New York, NY, USA). Methanol was purchased from Merck Química (Buenos Aires, Argentina). Molecular weight markers are Rainbow pre-stained molecular weight markers (Amersham Life Science, Buckinghamshire, UK). $\left[{ }^{3} \mathrm{H}\right] \mathrm{R} 5020$ and $\left[{ }^{3} \mathrm{H}\right] \mathrm{R} 5020$ were purchased from NEN (Boston, MA, USA) and $\mathrm{KCl}$ from Anedra (Buenos Aires, Argentina). Dithiothreitol, EDTA, sucrose, protease inhibitors, RU 486, and $E_{2}$ were purchased from Sigma (St. Louis, MO,
USA). ZK 299 was kindly provided by Schering (Berlin, Germany). Oligonucleotides were purchased from DNAgency (Malvern, PA, USA). They were designed to cover the translation initiation site of the target sequence. Synthetic, phosphorothiolated lyophilized oligonucleotides were dissolved in sterile saline solution, fractionated to a final concentration of $50 \mathrm{mg} / \mathrm{ml}$ and stored at $-20^{\circ} \mathrm{C}$. Approximately $30 \mathrm{~min}$ before each administration, oligodeoxynucleotides were further dissolved in saline. None of them exhibits homology with other reported sequences in GenBank.

\section{In vitro studies}

Studies were carried out using primary cultures from three different tumors (59-2-HI, CC4-HI, and C7-2-HI) [23]. Briefly, trypsinized tumor cells were seeded in multiwell plates; cell proliferation was evaluated 48 hours or 1 week after treatment by $\left[{ }^{3} \mathrm{H}\right]$ thymidine uptake or cell counting, respectively. All experiments were performed with Dulbecco's modified Eagle medium-F12 (Sigma) and steroid stripped fetal bovine serum. Oligodeoxynucleotides designed to block both $P R$ isoforms were used (5'-ACTCATGAGCGGGGACAACA-3') [24]. The scrambled oligonucleotide to PRs (scPR) 5'-ACGCTAGACTGACGACGAGA-3' was used as a control. [ $\left.{ }^{3} \mathrm{H}\right]$ thymidine uptake index was calculated as experimental counts per $\mathrm{min} /$ control counts per min.

The efficiency with which asPR blocked expression of PRs was evaluated in Western blots 24 hours after treatment, using the Ab7 (Neomarkers, Union City, CA, USA) antibody [22] or by binding techniques at single saturating concentrations with [ $\left.{ }^{3} \mathrm{H}\right] \mathrm{R} 5020$, as previously described [23]. NMuMG (murine mammary epithelial cells) [25] and uterus were used as negative and positive controls, respectively.

\section{In vivo experiments}

Tumor implants

Tumors were implanted subcutaneously into the right inguinal flank by trocar, as previously described [21]. Tumor growth was measured using a Vernier caliper (length and width). The product of these values was considered the tumor area. After the animals were killed, tumors were excised and weighed.

\section{Antiprogestin treatment}

When the tumors reached a size of approximately $25-50 \mathrm{~mm}^{2}$, animals were treated with daily doses of saline, ZK 299 (10 $\mathrm{mg} / \mathrm{kg})$, or RU $486(6.5 \mathrm{mg} / \mathrm{kg})$, as previously described [26]. Selected mice ( $n=3$ /group) were killed 24 hours after the first $\mathrm{RU} 486$ injection. In some experiments RU 486 was administered as silastic $5 \mathrm{mg}$ pellets, implanted subcutaneously. Tumor samples were fixed for histological evaluation and others were kept in liquid nitrogen for Western blot studies.

\section{Antisense treatment}

The treatments were started when the tumors reached 25-50 $\mathrm{mm}^{2}$. Two sets of experiments were performed. In the first, 
animals carrying $59-2-\mathrm{HI}$ or $32-2-\mathrm{HI}$ tumors were injected intraperitoneally with $1 \mathrm{mg}$ phosphorothiolated oligodeoxynucleotides to PR (i.e. asPR; volume $0.2 \mathrm{ml}$ ) or saline every 24 and 12 hours ( $n=3-4$ /group) for $59-2-\mathrm{HI}$ and 32-2-HI groups, respectively. All injections were prepared in sterile saline immediately before administration. Tumor size was evaluated every day, as described above. The estrous cycle was evaluated using vaginal smears, and the cycle in control animals was compared with those in RU 486-treated and ZK 299-treated animals. The animals were killed after 10 days and complete autopsies performed. Tumors were weighed and samples were immediately frozen or fixed in formalin. PR expression was evaluated using Western blots, as described below.

In the second set of experiments, the experiment ( $n=4$ /group) was repeated under the same conditions as described above but with the addition of two further groups: a third group of mice bearing 32-2-HI tumors and treated with scPR; and a fourth group treated with RU 486 in $5 \mathrm{mg}$ pellets implanted subcutaneously. The animals were inoculated every 12 hours with $1 \mathrm{mg}$ asPR and were killed after 5 days of treatment. Two hours before the animals were sacrificed, two animals in every group were injected with 5-bromodeoxyuridine (BrdU; 4 mg/ mouse). All samples fixed in formalin were embedded in paraffin using standard protocols, and $5 \mu \mathrm{m}$ sections were obtained and stained with heamatoxylin-eosin for histological examination.

\section{Progesterone receptor binding assays}

Binding of $\left[{ }^{3} \mathrm{H}\right] \mathrm{R} 5020$ to PRs was evaluated by whole cell assay. Briefly, $10^{5}$ cells were plated in 24 -well plates with Dulbecco's modified Eagle medium-F12 (Sigma) and 5\% steroid stripped fetal bovine serum. Treatments were initiated when cultures were half confluent; whole cell PR assays were performed after 24 hours, as previously described [23]. A total of 300,000 counts/min $17 \alpha$-methyl-[3H]R5020 were added together with a 100-fold excess of R5020 or ethanol. After 2 hours of incubation, the cells were washed, trypsinized, and counted in a liquid scintillation counter. A significant difference between counts per min in the groups incubated only with radioactive hormone and those incubated with radioactive plus unlabeled hormone yields the total counts per min bound to the receptors. These differences are directly proportional to the number of PRs in each experimental group.

\section{Preparation of whole cell extracts}

Uterus, muscle, and tumors were homogenized in a polytron at setting 50 with three bursts of $5 \mathrm{~s}$ in a 1:4 ratio of tissue:buffer. The buffer was $20 \mathrm{mmol} / \mathrm{I}$ Tris-HCl ( $\mathrm{pH} 7.4), 1.5 \mathrm{mmol} / \mathrm{I} \mathrm{EDTA}$, $0.25 \mathrm{mmol} / \mathrm{l}$ dithiothreitol, $20 \mathrm{mmol} / \mathrm{l} \mathrm{Na}_{2} \mathrm{MoO}_{4}$, and $10 \%$ glycerol. Protease inhibitors $(0.5 \mathrm{mmol} / /$ phenylmethylsulfonyl fluoride, $\quad 0.025 \mathrm{mmol} / \mathrm{l} \quad \mathrm{N}$-Carbobenzyloxy-L-phenylalanyl chloromethyl ketone, $0.025 \mathrm{mmol} / \mathrm{l}$ tosyl-lysylchloromethane, $0.025 \mathrm{mmol} / \mathrm{l}$ tosylphenylalanylchloromethane, and 0.025 $\mathrm{mmol} / \mathrm{l} \mathrm{N}_{\alpha}$-p-Tosyl-L-arginine methyl ester hydrochloride) were added to the buffer immediately before use. The homogenate was sonicated at medium frequency for $10 \mathrm{~s}$ (tubes were always kept on ice) and centrifuged for $45 \mathrm{~min}$ at $40,000 \mathrm{rpm}$ $\left(4^{\circ} \mathrm{C}\right)$. The supernatant was immediately frozen in liquid nitrogen and stored at $-70^{\circ} \mathrm{C}$ until later use in Western blot assays. Protein concentration was determined in accordance with the method proposed by Lowry and coworkers [27].

\section{Western blot}

The samples (100 $\mu \mathrm{g}$ total protein/lane) were separated on 7.5\% SDS-PAGE using Laemmli's buffer system [28]. The proteins were dissolved in sample buffer $(6 \mathrm{mmol} / \mathrm{l}$ (Tris $\mathrm{pH}$ 6.8), $2 \%$ SDS, $0.002 \%$ bromophenolblue, $20 \%$ glycerol, $5 \%$ mercaptoethanol) and boiled for $4 \mathrm{~min}$. After electrophoresis they were blotted onto a nitrocellulose membrane and blocked overnight in 5\% dry skimmed milk dissolved in phosphate-buffered saline (PBS)/Tween $0.1 \%(0.8 \% \mathrm{NaCl}, 0.02 \% \mathrm{KCl}$, $0.144 \% \mathrm{Na}_{2} \mathrm{PO}_{4}, 0.024 \% \mathrm{KH}_{2} \mathrm{PO}_{4}, \mathrm{pH} 7.4,0.1 \%$ Tween 20). Following several washes with PBS/Tween, the membranes were incubated with the primary antibody against PRs (Ab-7/ hPRa 7 (Neomarkers) or Ab-1 (kindly provided by Dr Gopalan Shyamala)), ER- $\alpha$ (MC-20; Santa Cruz Biotechnology, Santa Cruz, CA, USA), extracellular signal-regulated kinase (ERK; K23; Santa Cruz Biotechnology), phosphorylated (p)ERK (E-4; Santa Cruz Biotechnology), and E-cadherin (BD Transduction Lab, Palo Alto, CA, USA) at room temperature for 2 hours. Primary antibodies were used at 1:100 concentrations, except for E-cadherin, which was used at 1:10.000. Blots were probed with anti-mouse or anti-rabbit lgG, horseradish peroxidase-conjugated whole antibody (Amersham Life Science). The luminescent signal was generated with ECL Western blotting detection reagent kit (Amersham Pharmacia Biotech, Buckinghamshire, UK), and the blots were exposed to a medical X-ray film (Curix RP1; Agfa, Buenos Aires, Argentina) for $10 \mathrm{~s}$ to $5 \mathrm{~min}$. To control the efficiency of transference, membranes were stained with Ponceau S.

\section{Immunohistochemistry}

The sections were de-waxed in xylene, rehydrated through graded ethanols, and treated with $1 \%$ triton X-100 in PBS for $20 \mathrm{~min}$ at room temperature. They were then washed with PBS three times, $5 \mathrm{~min}$ each, and incubated for $30 \mathrm{~min}$ at room temperature with $3 \% \mathrm{H}_{2} \mathrm{O}_{2}$ in distilled water to quench endogenous peroxidase activity, washed extensively with PBS, and incubated in 3\% albumin or normal horse serum in PBS for $20 \mathrm{~min}$. The sections were then allowed to react with PRs (C-20; rabbit polyclonal lgG specific for PR; Santa Cruz Biotechnology) or ER (MC-20; rabbit polyclonal lgG specific for ER; Santa Cruz Biotechnology) diluted 1:100 in PBS for 48 hours at $4^{\circ} \mathrm{C}$ [25]. The slides were washed with PBS and successively incubated for $30 \mathrm{~min}$ at room temperature with anti-rabbit biotin-conjugated immunoglobulins (Vector Labs, San Francisco, CA, USA), diluted 1:250 in PBS, and, with the ABC complex, prepared according to the manufacturer's 
directions (Vector Labs). The slides were thoroughly washed with PBS and developed under microscopic control with 3-3' diaminobenzidine $0.06 \%$ in PBS and $\mathrm{H}_{2} \mathrm{O}_{2}$ at a final concentration of $0.1 \%$. Stained nuclei were counted in 15 high-power fields of each section using a 1000x magnification and expressed as mean \pm standard deviation of the percentage of the ratios between the total number of stained nuclei and the total cell number per high-power field.

5-BrdU was detected using a sheep polyclonal antibody (Maine Biotechnology Services Inc., Portland, ME, USA). Briefly, de-waxed and hydrated slides were permeabilized with proteinase K (Sigma; Cat\# 92905), $20 \mu \mathrm{g} / \mathrm{ml}, 15 \mathrm{~min}$ at room temperature. Enzyme action was stopped with 5\% normal horse serum in PBS and the slides were successively incubated with the anti-BrdU antibody diluted 1:200 in PBS, overnight at $4^{\circ} \mathrm{C}$, and washed and incubated with anti-sheep antibody (Vector) 1:400 in PBS. The slides were then processed through $A B C$ (Vector) and developed as described above. Apoptosis was evaluated using the standard in situ cell death detection Kit, Fluorescein (Roche; Cat\# 1684 795), in accordance with the manufacturer's instructions.

\section{Statistical analysis}

Analysis of variance followed by Tukey t-test was used to analyze the differences between control and experimental groups in $\left[{ }^{3} \mathrm{H}\right]$ thymidine uptake, tumor size, PR staining, and binding assays. Unpaired t-tests were used as needed. $P<0.05$ was considered statistically significant. Values are reported as mean \pm standard deviation. Tumor growth curves were also studied using regression analysis and slopes compared using analysis of variance followed by parallelism analysis.

\section{Results In vitro studies}

The role played by PRs in progestin-independent tumor growth was investigated in vitro using primary cultures of three different tumor cell lines from our model, as previously described [16,23]. RU 486 and ZK 299, two antiprogestins that exert their effects by different mechanisms, were able to inhibit cell proliferation, as evaluated by cell counting (not shown) and $\left[{ }^{3} \mathrm{H}\right]$ thymidine uptake (Fig. 1a), at concentrations as low as $1 \times 10^{-9} \mathrm{~mol} / \mathrm{l}$. Using the same experimental conditions, we investigated the effect of asPR. In concentrations above $1.25 \mu \mathrm{g} / \mathrm{ml}$, inhibition of cell proliferation was observed, as measured by $\left[{ }^{3} \mathrm{H}\right]$ thymidine uptake (Fig. $1 \mathrm{~b}$ ) or by cell counting (control: $64.75 \pm 3.84$; asPR $5 \mu \mathrm{g} / \mathrm{ml}$ : $38.25 \pm 1.14$ cells $\left./ \mathrm{ml} \times 10^{-4}\right)$. No effect was observed in the PR-negative NMuMG cells (not shown) or in tumor cells incubated with scPR (Fig. 1b).

AsPR treatment resulted in potent inhibition of PR binding ( $P$ $<0.01$ ) whereas ScPR had no effect (Fig. 1c). Western blot studies revealed that both $\mathrm{PR}$ isoforms were expressed to a lesser degree in asPR-treated cells (Fig. 1d).

\section{In vivo studies}

Tumor growth

The goal of this study was to extend our in vitro findings to an in vivo scenario. We showed that the tumors used in this study regressed completely after antiprogestin or estrogen treatment [16]. Our previous in vivo data pointed toward an essential role for PRs in tumor growth, but because estrogens induced the same inhibitory effect as antiprogestins, and antiprogestins were shown to exert estrogenic effects [29], the importance of PRs remained to be demonstrated. The aim of the following experiments was to evaluate whether tumor growth could be inhibited by blocking PR expression.

In a first set of experiments the progestin-independent tumor line $59-2-\mathrm{HI}$ was chosen because complete regression was induced with RU 486 and ZK 299, even in tumors with an initial size greater than $100 \mathrm{~mm}^{2}$ [26]. In this first experiment, asPR treatment $(1 \mathrm{mg} /$ day) began when tumors measured approximately $25 \mathrm{~mm}^{2}$ and continued for 10 days. AsPR inhibited tumor growth (not shown). No signs of nonspecific toxicity were detected by histopathological evaluation of organs. This experiment suggested that, although asPR inhibited tumor growth, the appropriate antisense dose could still be increased. Consequently, a second set of experiments was carried out using the 32-2-HI tumor, which also regresses completely after antiprogestin treatment (Fig. 2a), and the asPR dose was increased to $1 \mathrm{mg}$ twice daily. Figure $2 \mathrm{~b}$ shows that asPR treatment significantly inhibited tumor growth for 5 days, after which tumors resumed growth but at a slower rate.

From these experiments it was evident that asPR inhibited tumor growth. In a third set of experiments we included the control group using a scrambled sequence (scPR) and focused on short-term effects of asPR. In addition to tumor size, histopathological studies of tumors during the stationary phase were performed. As shown in Fig. 2 (panels $c$ and d) the differences in tumor size between asPR-treated animals and vehicle-treated or scPR-treated mice were significant. However, a more conspicuous decrease in tumor size was observed in RU 486-treated animals.

\section{Estrous cycle}

Vaginal smears were evaluated daily in RU 486-, ZK 299-, and asPR-treated animals. During the first week of treatment, AsPR-treated mice and antiprogestin-treated mice were in a continuous estrous/meta-estrous state; this effect of antiprogestins on the estrous cycle has been described by others $[30,31]$. After 1 week of treatment, asPR-treated mice started to cycle again, and interestingly tumors started to grow again. This transient effect of asPR treatment on the estrous cycle parallels the effect observed on tumor growth. $E_{2}$ serum levels in asPR-treated animals were undetectable by radioimmunoassay, whereas those in control animals were in the 
(a)

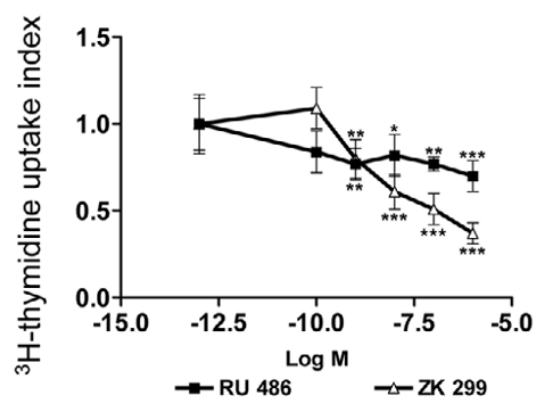

(c)

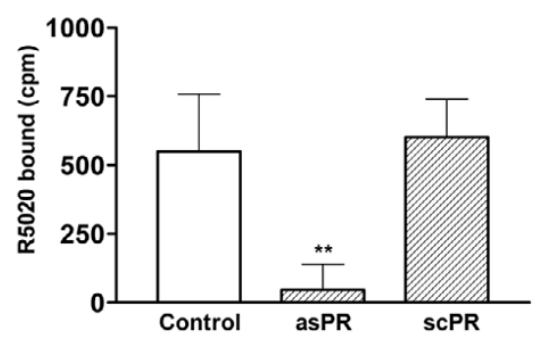

(b)

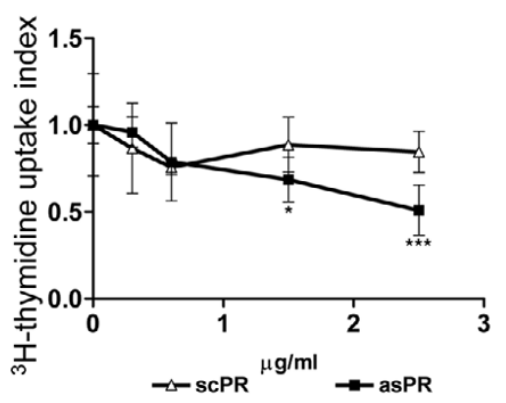

(d)

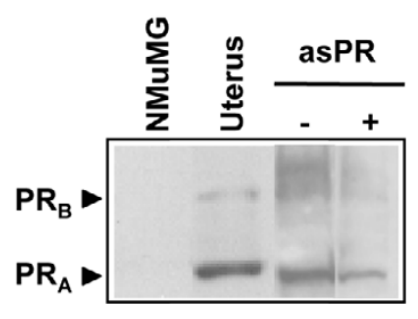

In vitro effects of asPR on primary cultures of progestin-independent tumors. Effect of (a) antiprogestins (RU 486, ZK 299) or (b) oligodeoxynucleotides to PR (asPR or ScPR) on [ $\left.{ }^{3} \mathrm{H}\right]$ thymidine uptake index on primary cultures of responsive progestin-independent tumor cells. The cells were incubated in Dulbecco's modifeid Eagle medium-F12 without phenol red, in the presence of $2.5 \%$ ssFCS and different drug concentrations for 48 hours. $\left[{ }^{3} \mathrm{H}\right]$ thymidine was added in the last 18 hours. These are representative experiments from at least three using three different tumors, with each value corresponding to the mean $\pm \mathrm{SD} \mathrm{cpm}$ of octuplicates. $\left[{ }^{3} \mathrm{H}\right]$ thymidine uptake index was calculated as the experimental $\mathrm{cpm} / \mathrm{control} \mathrm{cpm}$. ${ }^{*} P<$ $0.05,{ }^{* \star} P<0.01,{ }^{* \star \star} P<0.001$. (c) PR binding was evaluated in vitro using the whole cell binding assay in primary cultures from a responsive progestin-independent tumor in the presence of $2.5 \%$ ssFCS (control), scPR $(5 \mu \mathrm{g} / \mathrm{ml})$ or asPR $\left(5 \mu \mathrm{g} / \mathrm{ml} ;{ }^{*} P<0.01,{ }^{*} P<0.05\right)$. (d) PR Western blot analysis of cell extracts from the primary cultures grown in the presence of $2.5 \% \mathrm{ssFCS}(-)$ or asPR $(5 \mu \mathrm{g} / \mathrm{ml})$. Primary antibody: Ab-7 (mouse monoclonal; Neomarkers). NMuMG cell line and uterus were used as negative and positive controls, respectively. Experimental details are explained in Materials and method. asPR, antisense oligodeoxynucleotides to progesterone receptors; PR, progesterone receptor; scPR, scrambled oligodeoxynucleotides to progesterone receptors; SD, standard deviation; ssFCS, steroid stripped fetal calf serum.

expected range (not shown). Thus, the estrous state was not achieved because of higher $\mathrm{E}_{2}$ serum levels.

\section{Histopathology}

Tumor regression in this model progresses through cytostasis and apoptosis, leading to a progressive reduction in the epithelial compartment accompanied by an increase in stroma [26]. Histological signs of regression similar to those observed in the RU 486-treated tumors were seen in areas of asPRtreated mice (Fig. 3c,f) but not in vehicle-treated (Fig. 3a,d) and scPR-treated animals (Fig. $3 b, e$ ). The lesions revealed the presence of fibrosis; in areas the tumor was reduced to few strands of epithelial cells and occasional areas of calcification were observed. Althugh BrdU staining was similar between control and scPR-treated animals, absence of BrdU labeling was observed in one tumor (1/4) and a decrease in the other three tumors of asPR-treated mice (Fig. $3 g-i)$. A greater number of apoptotic cells, as shown by TUNEL (terminal deox- ynucleotidyl transferase mediated dUTP nick-end labeling) assay, were observed in regressing tumors (Fig. 3j-I).

To confirm the efficiency of asPR treatment in blocking expression of PRs, they were evaluated by immunohistochemistry in tumor samples as well as in normal mammary glands from treated and untreated mice (Fig. 3m-o). A significant decrease $(P<0.01)$ in PR staining was observed in tumors from asPR-treated mice as compared with tumors from control and scPR-treated mice. The percentage of stained nuclei was evaluated in $\mathbf{4 5}$ high-power fields from three different tumors (mean \pm standard deviation; control: $46 \pm 6.4 \%$; scPR: 44.7 $\pm 3 \%$; asPR: $11 \pm 1.3 \%$ ). No staining was observed using these antibodies in mammary glands from PR knockout mice [22]. Interestingly, no differences in PR (Fig. 4a-c) staining were observed in the mammary glands from asPR-treated, scPR-treated, or control mice, but glands from RU 486-treated mice exhibited only isolated PR immunoreactivity (Fig. 4d). 
(a)

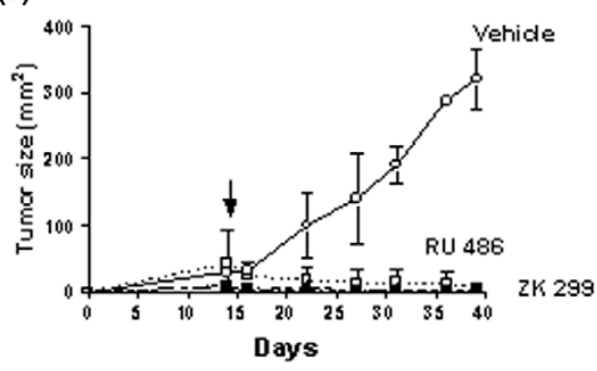

(c)

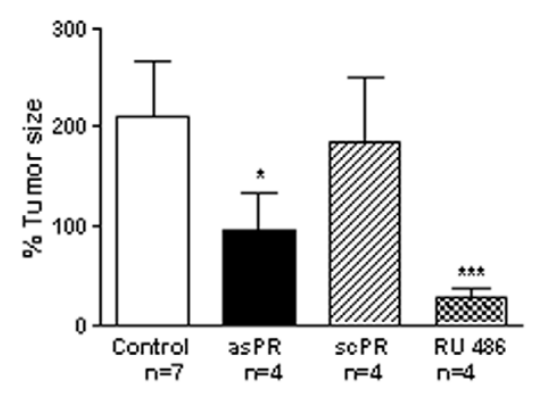

(b)

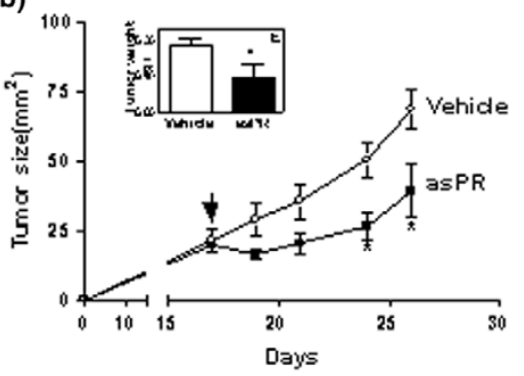

(d)

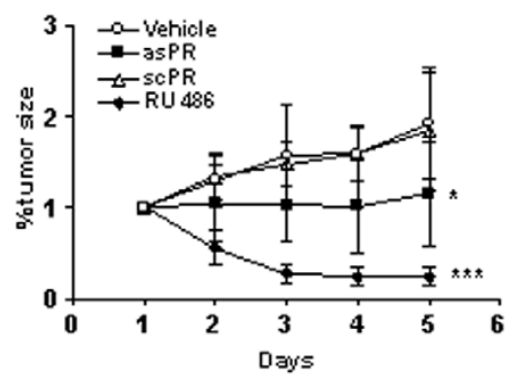

In vivo effect of asPR on progestin-independent tumor growth. (a) Effect of two different antiprogestins on tumor growth. Animals bearing tumors of size $25-50 \mathrm{~mm}^{2}$ were treated with RU $486(6.5 \mathrm{mg} / \mathrm{kg}$ body weight) or ZK 299 (10 mg/kg body weight subcutaneously) or saline. (b) Tumor growth in animals treated with saline $(n=7)$ or asPR $(n=3)$ administered in two daily doses of $1 \mathrm{mg}$ intraperitoneally $\left({ }^{\star} P<0.05\right)$. The differences in tumor growth rate are significantly different $(P<0.01)$. Inset: tumor weight at the end of the experiment, 11 days after treatment was initiated. (c,d) Effect of asPR ( $1 \mathrm{mg} / 12$ hours, intraperitoneally), scPR ( $1 \mathrm{mg} / 12$ hours, intraperitoneally), or RU 486 (6.5 mg/kg body weight, subcutaneously) on in vivo tumor growth. The percentage of the tumor size calculated as the final tumor area/tumor area at the beginning of the experiment (100\%) was evaluated on the last day of treatment (panel b) or throughout 5 days of treatment (panel c). asPR, antisense oligodeoxynucleotides to progesterone receptors; scPR, scrambled oligodeoxynucleotides to progesterone receptors. asPR, antisense oligodeoxynucleotides to progesterone receptors; scPR, scrambled oligodeoxynucleotides to progesterone receptors.

These results suggest that asPR may be more easily captured by tumor cells than by normal quiescent cells. Histopathological evaluation of lungs, kidney, liver, and spleen revealed no differences among groups (data not shown).

\section{PR, ER- $\alpha$, and ERK expression in RU 486-treated and asPR-treated tumors}

To further compare asPR and RU 486 treatments, we evaluated the expression of ER- $\alpha$ and ERKs in the same asPRtreated samples and in tumors treated with RU 486 for 24 hours. ER- $\alpha$ and pERK1 and pERK2 were decreased in both asPR-treated (Fig. 5a) and RU 486-treated tumors (Fig. 5b), whereas total MAPK levels remained unchanged. PR expression was also down-regulated in asPR-treated tumors (Fig. 5a), as previously shown by immunohistochemistry (Fig. 3mo), and in the 24-hour RU 486-treated tumors (Fig. 5b). To confirm that this downregulation was not an artifact associated with a decrease in epithelial cells, the expression of Ecadherin - a specific marker of epithelial cells - was used to evaluate the same control and 24-hour RU 486-treated tumor samples. As shown in Fig. 5b, the low levels in steroid receptor expression were not due to differences in the ratio of the epi- thelial cells. In addition, as shown in Fig. 5c, immunostaining of ER- $\alpha$ and PRs confirmed Western blot data.

\section{Discussion}

During the past few years the PR pathway has emerged as a likely player in the pathogenesis of breast cancer, with growing experimental as well as clinical evidence pointing to its protagonistic role [15]. Although estrogens remain the main foes in this story, interestingly most of the epidemiological evidence for their purported role as mammary carcinogens reflects prolonged exposure to female hormones, including progesterone. Among the abundance of data available, the results from the Women's Health Initiative [1] and the Million Women Study [2] are especially striking because they specifically link the use of progestins with breast cancer. Taking into account the literature attesting to the proliferative effect of progesterone on the mammary gland and the carcinogenic effect of MPA, it may be suggested that these results were predictable [3,4,32].

In this report, using an experimental model of mammary cancer, we demonstrate that the PR pathway is essential to maintenance of cell proliferation, even in tumors that are no longer 


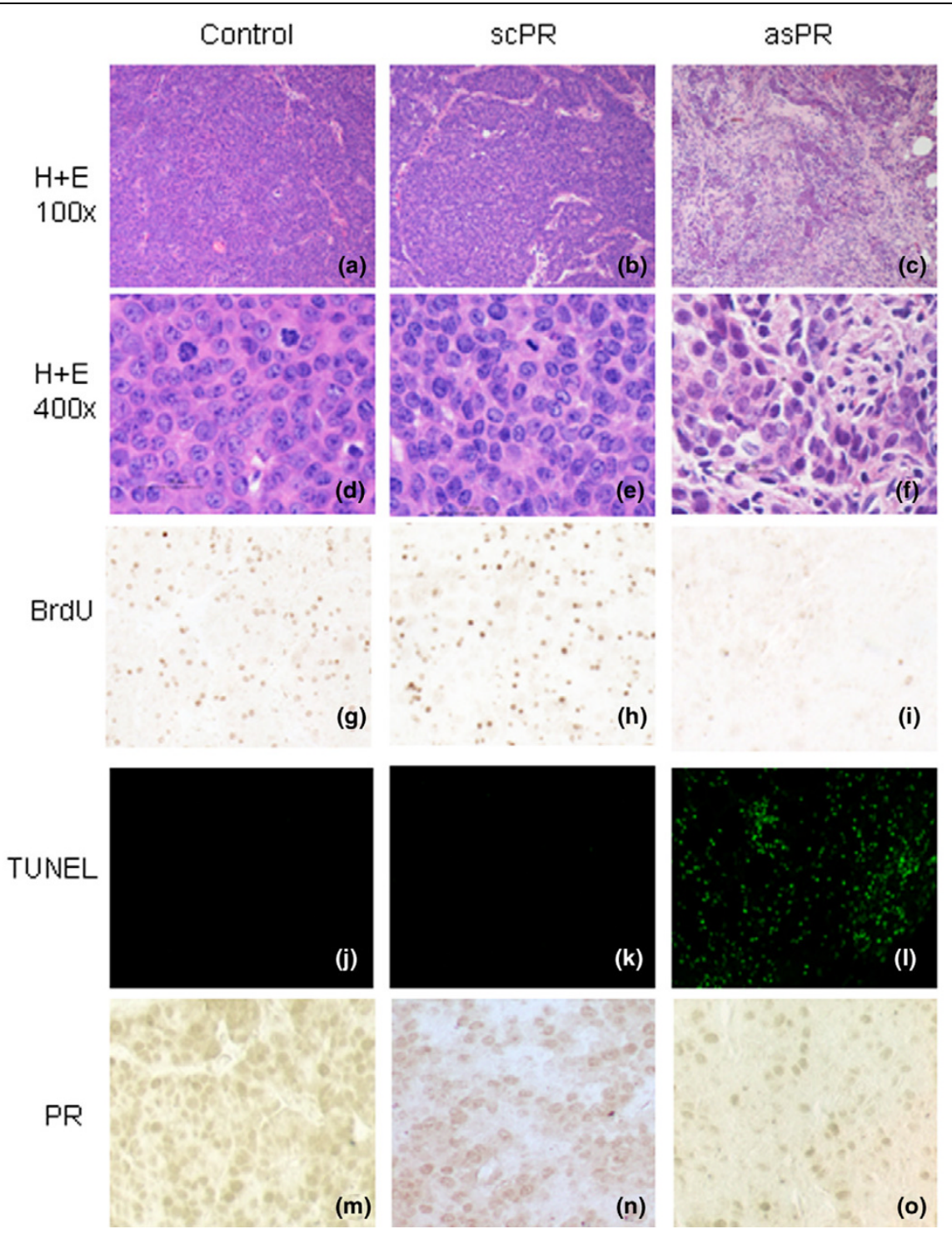

Morphological features and PR immunostaining in tumors treated with asPR or scPR for 5 days. Left column: control mice treated with saline; middle column: mice treated with scPR; right column: mice treated with asPR. (a-c) Hematoxylin and eosin (100x); (d-f) Hematoxylin and eosin (400x); (g-i) 5-BrdU immunocytochemistry; (j-l) TUNEL (100x); (m-o) PR immunohystochemistry. No changes were observed in tumors from animals treated with saline or scPR. Tumors from animals treated with asPR exhibit increasing degrees of fibrosis, as well as occasional lymphocytic infiltration. TUNEL staining, indicative of apoptosis, was only observed in asPR-treated tumors (panel i), in which also very few 5-BrdU stained nuclei were observed (panel f). Few PR stained nuclei are observed in asPR-treated tumors (panel I) as compared with control or scPR-treated tumors, in which most of the cells are positive (panels j and k, respectively). asPR, antisense oligodeoxynucleotides to progesterone receptors; PR, progesterone receptor; scPR, scrambled oligodeoxynucleotides to progesterone receptors; TUNEL, terminal deoxynucleotidyl transferase mediated dUTP nickend labeling.

dependent on progestins to grow. Even though our results do not provide additional data regarding the mechanisms underlying the role played by PRs in mediating tumor growth, they provide further support to our hypothesis and extend our previous data to the whole category of progestin-independent tumors. This experimental model shares many features with human breast cancer, in that the tumors are ductal metastatic carcinomas expressing high levels of ER- $\alpha$ and PR, which transit through different stages of hormone dependency. In addi- tion, tumors regress completely after antiprogestin or estrogen therapy and partially with tamoxifen [33]. The effectiveness of antiprogestins in tumor models other than ours, such as the rat MNU model or the mouse MXT model, has also been addressed by other authors [34].

There are no data available regarding the use of PRs as targets for gene therapy in breast cancer. Considering all of our previous findings, it seemed mandatory to try to inhibit the 
Figure 4
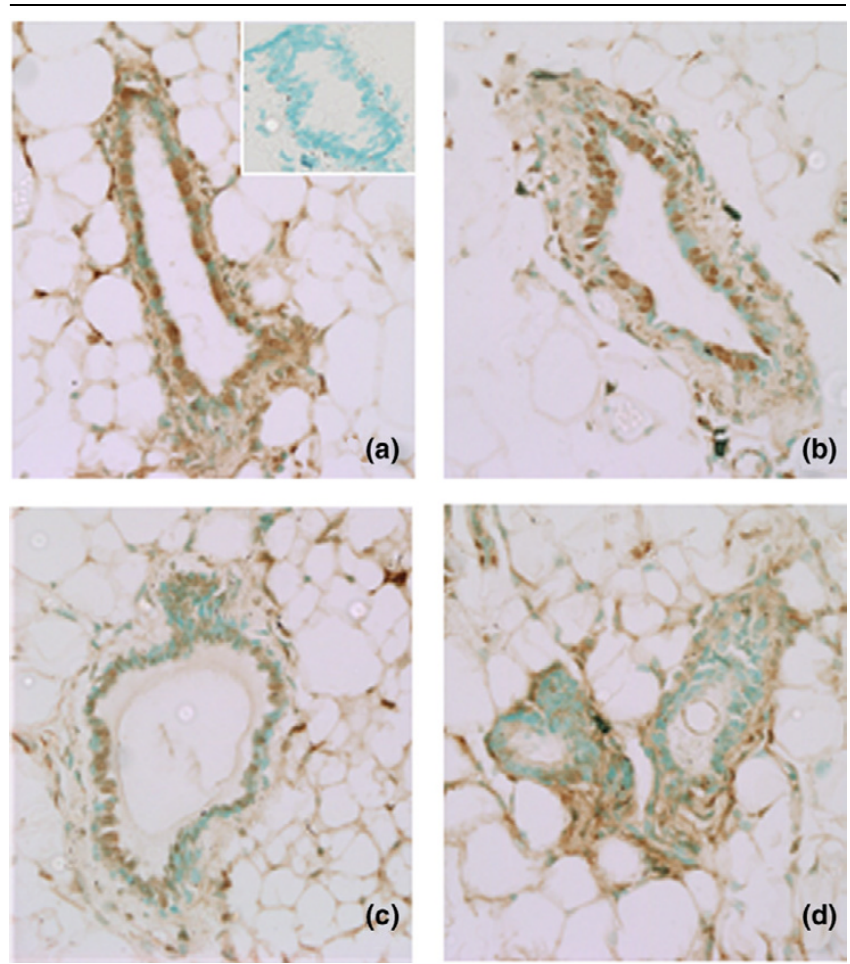

(b)

Effects of asPR or RU 486 on PR expression in mammary glands. Immunohistochemical staining for PR in sections of paraffin-embedded mammary glands of mice treated with (a) saline, (b) scPR, (c) asPR, or (d) RU 486 for 5 days. Inset: control, in which no primary antibody was added. Primary antibody: PR polyclonal (C-20; Santa Cruz Biotechnology). The procedure was performed as described in Materials and method. asPR, antisense oligodeoxynucleotides to progesterone receptors; PR, progesterone receptor; scPR, scrambled oligodeoxynucleotides to progesterone receptors.

expression of PRs and to demonstrate their role in an in vivo scenario. Because we were working with tumors and not with cell lines, we chose naked phosphorothiolated antisense oligonucleotides to PR. Using this approach, several genes such as ras, myc, mib, $m d m-2$ and bcr-abl, genes related to apoptotic functions such as $b c l-2$, and genes related to multidrug resistance have been blocked [35]. In all cases only incomplete blockade of protein expression was observed, and so only slight changes in tumor growth rate were evident. The results improved when combined therapies were applied [36].

In our experiments we achieved significant inhibition of tumor growth using one or two daily doses of $1 \mathrm{mg}$ asPR as compared with control or scPR-treated mice. No signs of toxicity were found at autopsy. Safety studies conducted in experimental animals have shown that repeated administration of phosphorothiolated oligonucleotides containing CpG dinucleotide motifs in a particular base context or $G$ quartets provoke adverse side effects due to cytokine release, decreased platelet counts and hepatotoxicity resulting from nonspecific immune stimulation [37]. The oligonucleotides used herein do not have CpG motifs but they do bear a G quartet; however, no signs of nonspecific immune reaction were observed on histological examination. The inhibitory effect on tumor growth correlated with a decrease in PR expression, but PR blockade was incomplete. This is in agreement with the partial inhibition of tumor growth and with results obtained by other groups using different antisense oligonucleotides [36,38]. It is also interesting that PR expression in mammary glands from asPRtreated mice was not affected to the degree that PRs from tumors were. The difference in effectiveness of the antisense therapy between tumors and normal tissues is an issue that has not been addressed in most studies [39-41]; on the other hand, it has been shown in in vitro studies that antisense treatment is less effective in normal cells than in the tumor cells [42]. From these observations it can be inferred that oligonucleotides may be more easily captured in a tumor environment than by quiescent cells. Although preliminary data obtained in our laboratory suggests that, in tumors implanted subcutaneously, there is an increased uptake of ${ }^{32} \mathrm{P}$-labeled oligonucleotides as compared with the normal mammary gland (not shown), this may be different in spontaneously arising tumors, which have a slower growth rate and abundant stroma.

Antiprogestins induce a continuous estrous or meta-estrous state [30]. Estrogen-like activities have been demonstrated for both antiprogestins, RU 486 [29], and ZK 299 [31,43] in both in vivo and in vitro studies. There has been concern from an endocrinological perspective over whether this effect was achieved because of a direct interaction of antiprogestins with ER- $\alpha$. The continuous estrus/meta-estrus state also observed in asPR-treated mice favors the notion that unopposed low estrogen levels may be responsible for inducing this uterotrophic effect [44]. These low $E_{2}$ levels are not the cause of tumor regression because these tumors grow similarly in ovariectomized animals.

Because ERK phosphorylation is among the signal transduction pathways involved in steroid-induced cell proliferation [45], we explored the expression of these proteins in RU 486treated and asPR-treated mice. An important decrease in pERK1 and pERK2 levels was evident after 24 hours of treatment when the tumors had already experienced a decrease in size. Similarly, in asPR-treated mice undergoing tumor regression, a decrease in pERK was observed, once again showing parallelism between RU 486-induced and asPR-induced tumor regression. ER- $\alpha$ expression exhibited the same kinetics. Absence of ER- $\alpha$ expression was observed in asPRtreated tumors and in RU 486-treated tumors after 24 hours. Immunohistochemistry studies confirmed results observed by Western blots ruling out the possibility that, although the same amount of protein was seeded, fewer epithelial cells expressing high levels of ER- $\alpha$ were masked. 
(a)

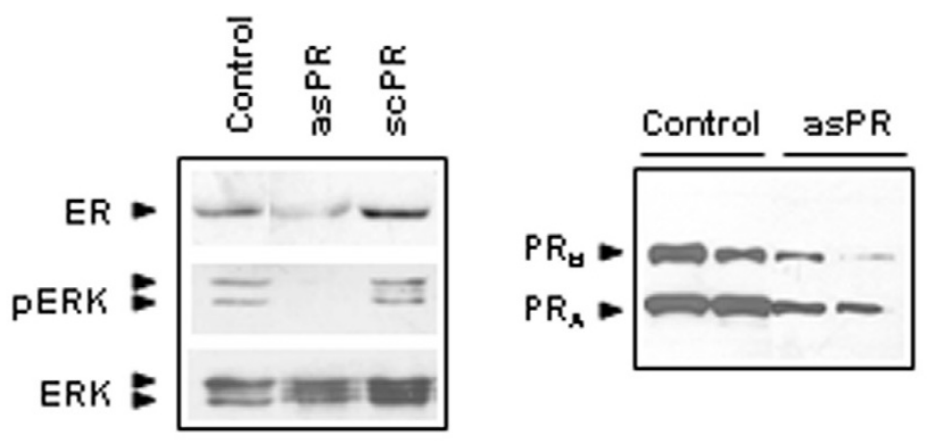

(b)
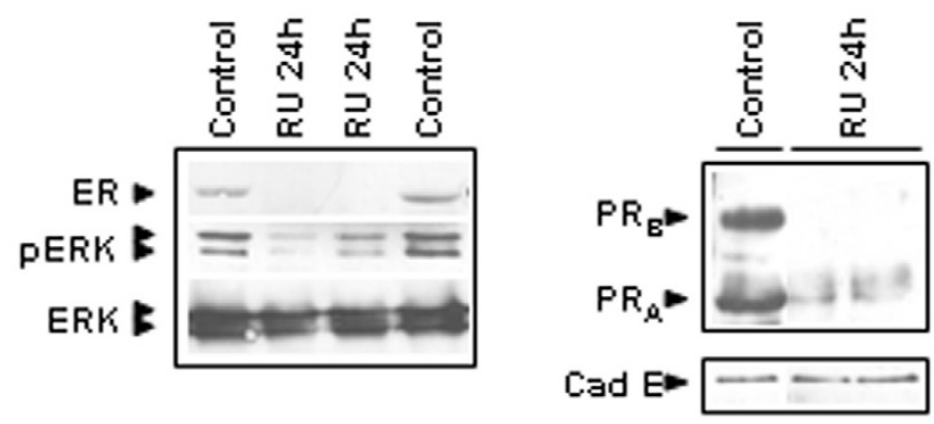

(c)

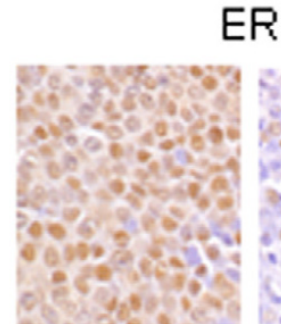

$0 \mathrm{~h}$
ER

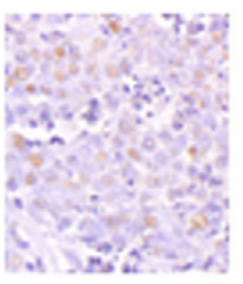

$24 \mathrm{~h}$

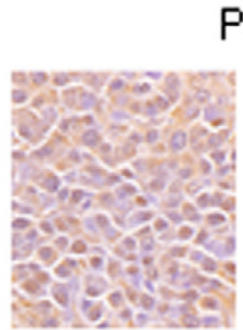

$0 \mathrm{~h}$
PR

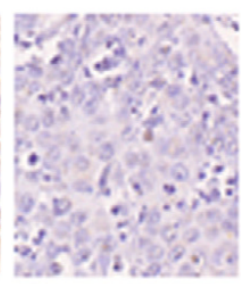

$24 \mathrm{~h}$

Effects of asPR or RU 486 on MAPK phosphorylation and on ER- $\alpha$ and PR expression. (a) Immunoblots of ER- $\alpha$ (MC-20; Santa Cruz Biotechnology), total ERK (K-23; Santa Cruz Biotechnology), and pERK (E-4; Santa Cruz Biotechnology) in whole extracts of tumors obtained from animals treated with saline, asPR, or scPR for 5 days. Tumor samples were obtained after day 5 of treatment; tumor growth kinetics is shown in Fig. $2 \mathrm{~d}$. Arrows show ERK1 $(42 \mathrm{kDa})$ and ERK2 $(44 \mathrm{kDa})$. PR immunoblots were performed using extracts obtained from mice treated with asPR over 10 days (Ab1; Dr Shyamala). Arrows show the classical PR $\mathrm{B}_{\mathrm{B}}$ of $115 \mathrm{kDa}$ and the classical $\mathrm{PR}_{\mathrm{A}}$ of $83 \mathrm{kDa}$. (b) Immunoblots of ER- $\alpha$, PR (Ab7; Neomarkers), E-cadherin (E cad; BD Transduction Lab), total ERK, and pERK using wholeextracts of tumors obtained from animals treated with saline or RU 486 for 24 hours. Tumor kinetics are shown in Fig. 2c. A representative Western blot of three is shown. (c) Immunohistochemistry of ER- $\alpha$ and PR (C-20 Santa Cruz) of the same tumor samples used in Western blot studies shown in panel b (125x). Experimental details are described in Materials and method. asPR, antisense oligodeoxynucleotides to progesterone receptors; ER, estrogen receptor; ERK, extracellular signal-regulated kinase; MAPK, mitogen-activated protein kinase; PR, progesterone receptor; scPR, scrambled oligodeoxynucleotides to progesterone receptors.

\section{Conclusion}

Our findings provide the first evidence that blockade of PRs using antisense oligonucleotides induces inhibition of tumor growth, and provide further evidence for a critical involvement of the stimulatory effects of the PR pathway in mammary cancer, supporting its choice as an alternative therapeutic target for those tumors bearing receptors that are unable to bind ligands.

\section{Competing interests}

The authors declare that they have no competing interests.

\section{Authors' contributions}

CAL carried out all of the in vitro experiments and, together with $\mathrm{LAH}$, participated in the in vivo experiments. SG and $\mathrm{LAH}$ carried out the Western blots assays. RS and SV participated in all immunohistochemical studies. CL and AM designed, 
coordinated, and drafted the manuscript. All authors read and approved the final manuscript.

\section{Acknowledgements}

We are grateful to Dr Gopalan Shyamala (Life Sciences Division, Lawrence Berkeley Laboratory, CA, USA) for providing the Ab-1 antibody; to Gador Laboratories for providing MPA; to Schering Laboratories for providing ZK 98299; to Jorge Vela and Dr Damasia Becu for the serum $E_{2}$ measurements; and to Miss Julieta Bolado for excellent technical assistance. This work was supported by Fundación Sales (Specific Grant 1999-2001) and SECYT (BID 1201/OC-AR, PICT 2002-0512276 and PICT 2003-05-14406).

\section{References}

1. Women's Health Initiative: Risks and benefits of estrogen plus progestin in healthy postmenopausal women: principal results From the Women's Health Initiative randomized controlled trial. JAMA 2002, 288:321-333.

2. Beral V, Million Women Study Collaborators: Breast cancer and hormone-replacement therapy in the Million Women Study. Lancet 2003, 362:419-427.

3. Hofseth LJ, Raafat AM, Osuch JR, Pathak DR, Slomski CA, Haslam SZ: Hormone replacement therapy with estrogen or estrogen plus medroxyprogesterone acetate is associated with increased epithelial proliferation in the normal postmenopausal breast. J Clin Endocrinol Metab 1999, 84:4559-4565.

4. Ross RK, Paganini-Hill A, Wan PC, Pike MC: Effect of hormone replacement therapy on breast cancer risk: estrogen versus estrogen plus progestin. J Natl Cancer Inst 2000, 92:328-332.

5. Lydon JP, Ge G, Kittrell FS, Medina D, O'Malley BW: Murine mammary gland carcinogenesis is critically dependent on progesterone receptor function. Cancer Res 1999, 59:4276-4284.

6. Kordon EC, Molinolo AA, Pasqualini CD, Charreau EH, Pazos P, Dran G, Lanari C: Progesterone induction of mammary carcinomas in BALB/c female mice. Correlation between progestin dependence and morphology. Breast Cancer Res Treat 1993, 28:29-39.

7. Lanari $C$, Molinolo $A A$, Pasqualini CD: Induction of mammary adenocarcinomas by medroxyprogesterone acetate in BALB/ c female mice. Cancer Lett 1986, 33:215-223.

8. Pazos P, Lanari C, Meiss R, Charreau EH, Pasqualini CD: Mammary carcinogenesis induced by $\mathrm{N}$-methyl- $\mathrm{N}$-nitrosourea (MNU) and medroxyprogesterone acetate (MPA) in BALB/c mice. Breast Cancer Res Treat 1992, 20:133-138.

9. Pazos $\mathrm{P}$, Lanari $\mathrm{C}$, Charreau EH, Molinolo AA: Promoter effect of medroxyprogesterone acetate (MPA) in N-methyl-N-nitrosourea (MNU) induced mammary tumors in BALB/c mice. Carcinogenesis 1998, 19:529-531.

10. Aldaz CM, Liao OY, Paladugu A, Rehm S, Wang H: Allelotypic and cytogenetic characterization of chemically induced mouse mammary tumors: high frequency of chromosome 4 loss of heterozygosity at advanced stages of progression. Mol Carcinog 1996, 17:126-133.

11. Kordon E, Lanari C, Meiss R, Charreau E, Pasqualini CD: Hormone dependence of a mouse mammary tumor line induced in vivo by medroxyprogesterone acetate. Breast Cancer Res Treat 1990, 17:33-43.

12. Molinolo AA, Lanari C, Charreau EH, Sanjuan N, Pasqualini CD: Mouse mammary tumors induced by medroxyprogesterone acetate: immunohistochemistry and hormonal receptors. J Natl Cancer Inst 1987, 79:1341-1350.

13. Lanari C, Kordon E, Molinolo A, Pasqualini CD, Charreau EH: Mammary adenocarcinomas induced by medroxyprogesterone acetate: hormone dependence and EGF receptors of BALB/c in vivo sublines. Int J Cancer 1989, 43:845-850.

14. Lanari C, Montecchia MF, Pazos P, Simian M, Vanzulli S, Lamb C, Molinolo AA: Progestin-induced mammary adenocarcinomas in BALB/c mice. Progression from hormone-dependent to autonomous tumors. Medicina (B Aires) 1997, 57:55-69.

15. Lanari $C$, Molinolo A: Progesterone receptors - animal models and cell signalling in breast cancer. Diverse activation pathways for the progesterone receptor: possible implications for breast biology and cancer. Breast Cancer Res 2002, 4:240-243.

16. Montecchia MF, Lamb C, Molinolo AA, Luthy IA, Pazos P, Charreau $E$, Vanzulli $S$, Lanari $C$ : Progesterone receptor involvement in independent tumor growth in MPA-induced murine mammary adenocarcinomas. J Steroid Biochem Mol Biol 1999, 68:11-21.

17. Lamb C, Simian M, Molinolo A, Pazos P, Lanari C: Regulation of cell growth of a progestin-dependent murine mammary carcinoma in vitro: progesterone receptor involvement in serum or growth factor-induced cell proliferation. J Steroid Biochem Mol Biol 1999, 70:133-142.

18. Labriola L, Salatino M, Proietti CJ, Pecci A, Coso OA, Kornblihtt AR, Charreau EH, Elizalde PV: Heregulin induces transcriptional activation of the progesterone receptor by a mechanism that requires functional ErbB-2 and mitogen-activated protein kinase activation in breast cancer cells. Mol Cell Biol 2003, 23:1095-1111.

19. Qiu M, Olsen A, Faivre E, Horwitz KB, Lange CA: Mitogen activated protein kinase regulates nuclear association of human progesterone receptors. Mol Endocrinol 2003, 17:628-642.

20. Institute of Laboratory Animal Resources CoLSNRC: Guide for the Care and Use of Laboratory Animals Washington, DC: National Academy Press; 1996.

21. Kordon EC, Guerra F, Molinolo AA, Charreau EH, Pasqualini CD, Pazos P, Dran G, Lanari C: Effect of sialoadenectomy on medroxyprogesterone-acetate-induced mammary carcinogenesis in BALB/c mice. Correlation between histology and epidermal-growth-factor receptor content. Int J Cancer 1994, 59:196-203.

22. Helguero LA, Viegas M, Asaithamby A, Shyamala G, Lanari C, Molinolo AA: Progesterone receptor expression in medroxyprogesterone acetate-induced murine mammary carcinomas and response to endocrine treatment. Breast Cancer Res Treat 2003, 79:379-390.

23. Dran G, Luthy IA, Molinolo AA, Charreau EH, Pasqualini CD, Lanari C: Effect of medroxyprogesterone acetate (MPA) and serum factors on cell proliferation in primary cultures of an MPAinduced mammary adenocarcinoma. Breast Cancer Res Treat 1995, 35:173-186.

24. Mani SK, Blaustein JD, Allen JM, Law SW, O'Malley BW, Clark JH: Inhibition of rat sexual behavior by antisense oligonucleotides to the progesterone receptor. Endocrinology 1994 135:1409-1414.

25. Lanari C, Luthy I, Lamb CA, Fabris V, Pagano E, Helguero LA, Sanjuan N, Merani S, Molinolo AA: Five novel hormone-responsive cell lines derived from murine mammary ductal carcinomas: in vivo and in vitro effects of estrogens and progestins. Cancer Res 2001, 61:293-302.

26. Vanzulli S, Efeyan A, Benavides F, Helguero L, Peters G, Shen J, Conti CJ, Lanari C, Molinolo A: p21, p27 and p53 in estrogen and antiprogestin-induced tumor regression of experimental mouse mammary ductal carcinomas. Carcinogenesis 2002, 23:749-757.

27. Lowry $\mathrm{OH}$, Rosebrough NJ, Farr AL: Protein measurements with the Folin phenol reagent. J Biol Chem 1951, 193:265-275.

28. Laemmli UK: Cleavage of structural proteins during the assembly of the head of bacteriophage T4. Nature 1970, 227:680-685.

29. Brenner RM, Slayden OD: Oestrogen action in the endometrium and oviduct of rhesus monkeys during RU486 treatment. Hum Reprod 1994, 9(Suppl 1):82-97.

30. Gao Y, Short RV: Fertility control in wild mice after feeding with RU486 or methyl testosterone. J Reprod Fertil 1994, 101:483-487.

31. Hyder SM, Chiappetta C, Stancel GM: Induction of the angiogenic factor VEGF in the uterus by the antiprogestin onapristone. Cancer Lett 2000, 156:101-107.

32. World Health Organization: IARC Monographs on the Evaluation of Carcinogenic Risk to Humans: Hormonal Contraception and Post-menopausal Hormonal Therapy Lyon, France: IARC Scientific Publications, World Health Organization; 1999.

33. Lamb CA, Helguero LA, Fabris V, Lucas C, Molinolo AA, Lanari C: Differential effects of raloxifene, tamoxifen and fulvestrant on a murine mammary carcinoma. Breast Cancer Res Treat 2003, 79:25-35.

34. Michna H, Schneider MR, Nishino $Y$, el Etreby MF: Antitumor activity of the antiprogestins ZK 98.299 and RU 38.486 in hor- 
mone dependent rat and mouse mammary tumors: mechanistic studies. Breast Cancer Res Treat 1989, 14:275-288.

35. Pawlak W, Zolnierek J, Sarosiek T, Szczylik C: Antisense therapy in cancer. Cancer Treat Rev 2000, 26:333-350.

36. Bianco R, Caputo R, Caputo R, Damiano V, De Placido S, Ficorella C, Agrawal S, Bianco AR, Ciardiello F, Tortora G: Combined targeting of epidermal growth factor receptor and MDM2 by gefitinib and antisense MDM2 cooperatively inhibit hormoneindependent prostate cancer. Clin Cancer Res 2004, 10:4858-4864.

37. Stahel RA, Zangemeister-Wittke U: Antisense oligonucleotides for cancer therapy-an overview. Lung Cancer 2003, 41(Suppl 1):S81-S88.

38. Wang $H$, Zeng $X$, Oliver $P$, Le LP, Chen J, Chen L, Zhou W, Agrawal S, Zhang R: MDM2 oncogene as a target for cancer therapy: An antisense approach. Int J Oncol 1999, 15:653-660.

39. Salatino M, Schillaci R, Proietti CJ, Carnevale R, Frahm I, Molinolo $\mathrm{AA}$, Iribarren A, Charreau EH, Elizalde PV: Inhibition of in vivo breast cancer growth by antisense oligodeoxynucleotides to type I insulin-like growth factor receptor mRNA involves inactivation of ErbBs, PI-3K/Akt and p42/p44 MAPK signaling pathways but not modulation of progesterone receptor activity. Oncogene 2004, 23:5161-5174.

40. Gleave M, Nelson C, Chi K: Antisense targets to enhance hormone and cytotoxic therapies in advanced prostate cancer. Curr Drug Targets 2003, 4:209-221.

41. Geiger T, Muller M, Dean NM, Fabbro D: Antitumor activity of a PKC-alpha antisense oligonucleotide in combination with standard chemotherapeutic agents against various human tumors transplanted into nude mice. Anticancer Drug Des 1998, 13:35-45.

42. Elez R, Piiper A, Kronenberger B, Kock M, Brendel M, Hermann E, Pliquett U, Neumann E, Zeuzem S: Tumor regression by combination antisense therapy against Plk1 and Bcl-2. Oncogene 2003, 22:69-80.

43. Bigsby RM, Young PC: Estrogenic effects of the antiprogestin onapristone (ZK98.299) in the rodent uterus. $A m$ J Obstet Gynecol 1994, 171:188-194.

44. Chwalisz K, Stockemann K, Fritzemeier KH, Fuhrmann U: Modulation of oestrogenic effects by progesterone antagonists in the rat uterus. Hum Reprod Update 1998, 4:570-583.

45. Santen RJ, Song RX, McPherson R, Kumar R, Adam L, Jeng MH, Yue W: The role of mitogen-activated protein (MAP) kinase in breast cancer. J Steroid Biochem Mol Biol 2002, 80:239-256. 